\title{
Entre no-ficción y novela histórica: ambigüedad y eficacia en Noviembre, de Jorge Galán
}

\author{
Robin Lefere ${ }^{1}$
}

Resumen. Noviembre (2015), de Jorge Galán, evoca e indaga desde el presente el asesinato, en noviembre de 1989, del jesuita español Ignacio Illacuría y de todos los testigos presentes en el Centro Monseñor Romero de la Universidad Centroamericana de San Salvador. El libro ha sido presentado, por el autor y la crítica, como una novela (ni siquiera histórica). Sin embargo, semejante adscripción genérica resulta muy dudosa: hay más argumentos para calificar ese texto como no-ficción. En realidad, nos encontramos con un caso específico de poética híbrida cuya ambigüedad se revela especialmente eficaz en lo que se refiere al compromiso de lucha contra el olvido, la omisión y la tergiversación de la historia, y en la construcción de la memoria colectiva.

Palabras clave: No-ficción; novela histórica; poética híbrida; Jorge Galán; Ignacio Ellacuría.

[en] Between Non-Fiction and Historical Novel: Ambiguity and Efficieny in Jorge Galán's Noviembre

Abstract. November (2015), by Jorge Galán, evokes and enquires from the present the murder, in November 1989, of Spanish Jesuit Ignacio Illacuría, including all witnesses at the Monseñor Romero Centre, located in the Centro American University of San Salvador. The book was introduced, by the author and critics, as a novel (not even a historic one). However, such generic classification seems rather dubious: it includes more arguments to categorise the text as non-fiction. Actually, we face a specific case of hybrid poetics, which ambiguity reveals itself fairly effective in its compromise to fight against the oblivion, the omission and distortion of the story, contributing to build up collective memory.

Keywords: Non-fiction; historical novel; hybrid poetry, Jorge Galán; Ignacio Ellacuría.

Cómo citar: Lefere, R. (2020) Entre no-ficción y novela histórica: ambigüedad y eficacia en Noviembre, de Jorge Galán, en Anales de Literatua Hispanoamericana 49, 269-274.

[...] la narrativa, como ninguna otra expresión artística, ha asumido un papel protagónico en la lucha contra el olvido,

la omisión y la tergiversación de la historia, y en la construcción de la memoria colectiva.

(Mackenbach et alii, 2008: 5)

En octubre de 2016, el escritor salvadoreño Jorge Galán (seudónimo literario de George Alexander Portillo) ganó el Premio Real Academia Española por su libro Noviembre que acababa de publicarse en España bajo el sello de Tusquets (en 2015 había salido en Planeta México). El premio estimuló reseñas, presentaciones y entrevistas, en las que se destacaba ante todo el argumento histórico del libro: tematiza la Historia reciente del Salvador y, en particular, el asesinato, el 16 de noviembre de 1989, del jesuita español Ignacio Ellacuría y de todos los testigos presentes en el Centro Monseñor Romero de la Universidad Centroamericana de San Salvador. También se señalaba el vínculo temático con el poemario Bajo la interminable noche de 
noviembre, que el mes anterior, en septiembre de 2016, había sido distinguido con el XVI Premio Casa de América de Poesía Americana ${ }^{2}$. Por lo tanto, cabía la perspectiva, siempre prometedora desde el punto de vista teórico, de contrastar dos modalidades de acercamiento literario (prosa y poesía) a un mismo tema. Sin embargo, de los comentarios se desprendía un tercer aspecto, no explicitado pero más sugerente aún, en que voy a centrarme aquí: la ambigüedad de la (supuesta) novela Noviembre.

En efecto, la nota de la Real Academia decía "novela", los periodistas que le dieron eco al premio repetían "novela", pero al mismo tiempo recalcaban que ésta se centraba en un acontecimiento que conmovió al mundo entero, hacían hincapié en la reconstrucción escrupulosa del contexto y la investigación del autor (curiosamente sin utilizar nunca el marbete de "novela histórica"), y terminaban destacando que Jorge Galán había tenido que exiliarse de su país por las amenazas de muerte que el libro provocó en El Salvador ${ }^{3} .$. Es suficiente para despertar una duda: ¿estamos hablando de una verdadera novela?

Al abrir el libro premiado (la edición de Tusquets, que será mi referencia), se observa que el texto de la cubierta posterior, las valoraciones de escritores o periodistas reproducidas en la solapa posterior, así como los "Agradecimientos" del autor (275) califican Noviembre como "novela". Sin embargo, en estos mismos agradecimientos Jorge Galán destaca "las valiosas investigaciones" y los numerosos "testimonios valiosísimos" que "hicieron posible este libro". En las presentaciones en los medios de comunicación, el autor utiliza siempre la palabra "novela", pero llega a puntualizar que se limita a "contar lo que pasó", dándoles la palabra a muchos testigos, con la intención de mantener viva o incluso rescatar la memoria de aquella tragedia y la figura ejemplar de los jesuitas, ante todo para los salvadoreños de hoy y con la esperanza de contribuir a que se salga de la perpetua situación de impunidad. Cuando, por otra parte, en el programa "Conversatorios en Casa de América" (27 de abril de 2017), el periodista Antonio Gárate habla de "novela de no ficción", Galán no le rectifica". Por último, a poco que uno se adentre en el libro, la ambigüedad no hace sino confirmarse, y las dudas acerca del estatuto genérico van en aumento: ¿"novela", "novela histórica", "novela de no-ficción"? ¿O ninguna de estas categorías? Noviembre ofrece, pues, un caso muy interesante para volver a plantear la cuestión de las relaciones entre los géneros mencionados $\mathrm{y}$, al mismo tiempo, la problemática tan actual como fundamental de las relaciones entre "fiction et diction" (G. Genette), la cual resulta especialmente intricada cuando se trata de libros que, como el de Galán, tematizan la Historia ${ }^{5}$.

No me parece que se pueda calificar Noviembre como "novela" a secas, por lo menos si concebimos la novela como una ficción, y ésta como lo hace por ejemplo Françoise Lavocat en su monografía de 2016 (Fait et fiction. Pour une frontière): "artefact culturel produit par l'imagination et non soumis aux conditions de vériconditionnalité fondées sur la référence au monde empirique" (33). En Noviembre, Jorge Galán no inventa sustancialmente nada: ni los acontecimientos, ni los personajes ${ }^{6}$, ni las circunstancias; la materia de su narración proviene de la memoria personal ${ }^{7}$ y colectiva, sobre todo de testimonios, y de monografías solventes (en los ya mentados "Agradecimientos" señala las investigaciones de Martha Doggett y Teresa Whitfield $)^{8}$. Tampoco encontramos una intriga novelesca distinta de la intriga histórica ${ }^{9}$ : se arma un vaivén

${ }^{2}$ El volumen se publicó en Visor con el título Medianoche del mundo. Consta de dos partes: "La interminable noche de noviembre” y “Geografía”. En realidad, un solo poema, "La huida", tematiza el drama de 1989, centrándose en el exilio del yo lírico (cf. 12-13).

${ }^{3}$ Indico aquí las pautas más frecuentes de las reseñas a las que he tenido acceso. El interés de la mayoría es sólo circunstancial, y por eso no las específico (destacaré algunas posteriormente); la nota de la RAE puede ser consultada en su página web: https://www.rae.es/noticias/noviembrede-jorge-galan-premio-rae-2016.

4 Disponible en la red: http://www.rtve.es/alacarta/videos/conversatorios-en-casa-de-america/conversatorios-casa-america-jorge-galan/3999278/ (véase en particular 12'26").

${ }^{5}$ Salvo error de mi parte, no existen aún estudios propiamente dichos de Noviembre. Sin embargo, para un comentario global, especialmente atinado y sensible, recomiendo la presentación y entrevista de la profesora (UAB) y escritora salvadoreña Tania Pleitez Vela (2015), quien, por cierto, habla de "no-ficción" (sin desarrollar). También pueden consultarse otras dos reseñas que acompañan entrevistas: las de Teresa Iribarren (2016) y Dante Liano (2017).

${ }^{6}$ ¿Hay personajes totalmente ficticios (es, decir, que no sean transposiciones ficcionales de personas reales) en Noviembre? Desde luego, ningún personaje de primera fila. Quizás en las familias de Miguel y Juan (respectivamente en la segunda y la cuarta parte).

${ }^{7}$ En 1989 Galán tenía apenas 16 años pero en entrevistas y presentaciones precisó que estudió en la Universidad Central y que ahí mucho se hablaba aún del martirio de los jesuitas.

${ }^{8}$ Autoras respectivamente de Death Foretold: The Jesuit Murders in El Salvador (1993) y Paying the Price: Ignacio Ellacuría and the Murdered Jesuits of El Salvador (1994).

${ }^{9}$ En contra de lo que D. Cohn denomina, con B. Harshaw, el principio del "double-decker", característico de la ficción (2001: 31 ); es decir, un marco interno de referencia (el de la intriga ficticia) insertado dentro de un marco externo de referencia (el del mundo no ficcional). En efecto, si es de tipo realista (lato sensu), la novelación supone, en paralelo con el proceso de referenciación (hacer referencia, dentro del texto, a una realidad extratextual), un proceso de ficcionalización, que introduce una tensión entre marcos de referencia externo e interno, e incluso supedita el primero al segundo (imperativo estético). Para un desarrollo sistemático, véase "Del pensar de la novela histórica" (Lefere 2013: 151-162). 
entre la evocación de los acontecimientos históricos y las entrevistas que veinticinco años más tarde el narrador les hizo a distintos protagonistas de aquéllos ${ }^{10}$. Estas entrevistas no son imaginarias: el autor se refiere a ellas en los "Agradecimientos" y, por otra parte, en las charlas y presentaciones ${ }^{11}$. Además, menciona los nombres exactos de esos testigos de primera línea: los Padres Jesuitas Tojeira y Sobrino, el ex presidente Alfredo Cristiani... Llama la atención la atrevida ausencia de cualquier "disclaimer"12, teniendo en cuenta que Galán nombra también, siguiendo el informe de la Comisión de la Verdad, a los presuntos responsables de la masacre (cf. 237) -lo cual, de hecho, acabó forzando el exilio.

Es cierto que, si en vez de "novela" a secas habláramos de "novela histórica", todo esto resultaría menos incongruente, puesto que la novela histórica, de por sí (al menos cuando es novela histórica propiamente dicha y no mero exotismo temporal), se nutre de una realidad histórica extratextual (como, por cierto, la novela tradicionalmente llamada "realista") ${ }^{13}$. Pero, en principio, la novela histórica, en cuanto novela, reivindica su autonomía estética; tiende a emanciparse de la "realidad histórica" (la construida por los historiadores o un consenso social) para construir su propia realidad novelesca, y tiende a sobreponer a la intencionalidad extrarreferencial una intencionalidad simbólica: pensemos en los títulos mismos El general en su laberinto o La fiesta del Chivo (por mencionar dos novelas muy conocidas). En el caso de Noviembre, Galán reivindica antes que nada la intencionalidad extrarreferencial (veracidad factual y veracidad de los retratos $)^{14}$, y además una intencionalidad pragmática, que se manifiesta por ejemplo en el "Epílogo" (269274):

Han pasado más de veinte años desde aquella conversación. A lo largo de todo este tiempo, el Gobierno español ha intentado extraditar a los verdaderos culpables de la masacre. El Gobierno salvadoreño se ha negado en todas esas ocasiones. Los nombres han sido dichos. Diversas investigaciones han llegado a conclusiones sobre los verdaderos responsables. En ocasiones, todo parece avanzar. En otras, todo parece estar perdido. (271)

Un párrafo como éste, y por otra parte los muchos párrafos meramente informativos que encontramos a lo largo de la narración y que recuerdan contextos y circunstancias (cf. 95, 105, 117, 154, 156, 185, 189, 193, 204-208, 222-225...), ponen en entredicho el principio de autonomía de la ficción, hasta el punto de que podemos dudar de que se trate siquiera de un texto "básicamente ficcional" -por convocar ahora un concepto más amplio de lo que es ficción, limitado a criterios formales e internos. En efecto, si acudimos al estudio clásico de Kate Hamburger, y a su criterio, luego retomado por Dorrit Cohn, de desvinculación del mundo extratextual, con la organización correspondiente de un espacio-tiempo autónomo y la presentación de personajes autónomos que funcionan como "yo-orígenes" (cf. Cohn: 43-44), aquí no se observa tal desvinculación. Si, por otra parte, acudimos al criterio principal de Gérard Genette (1991: 82-84), no resulta nada evidente la distinción entre el autor Jorge Galán y el narrador-investigador de Noviembre; es cierto que el narrador no se nombra, pero casi todo, en el texto, el paratexto y el peritexto apunta a la continuidad entre mundo textual y mundo extratextual; y, desde luego, haciendo uso de otro criterio manejado por D. Cohn (57-58), no se percibe ninguna discrepancia entre los valores del narrador y los del autor (tales como éstos se manifiestan en las presentaciones y entrevistas).

Ahora bien, si Noviembre no se puede considerar como una ficción, ni siquiera como un texto básicamente ficcional, y por lo tanto no debería ser calificada como "novela", ni siquiera como "novela

${ }^{10}$ De la p. 48 se desprende que las entrevistas se hicieron en 2014, salvo en el caso de Francisco Andrés Escobar (en 1993 -cf. "Epílogo").

11 Varias han sido grabadas, y colgadas en you tube; por ejemplo, la presentación en Valladolid del 20 de octubre de 2016 (https://www.youtube.com/watch?v=Mnja0oEk-I).

${ }^{12}$ A diferencia de Disparo en la catedral (1997) -primera novela, escrita en los USA, del salvadoreño Mario Bencastro- que empieza con esta “Aclaración” del autor: "A excepción del período histórico de El Salvador que comprende esta novela (julio 1979 a marzo 1980), al igual que las homilías de Monseñor Oscar A. Romero, su asesinato y funerales, el resto de los nombres, personajes, lugares e incidentes son creación del autor, o han sido usados en forma ficticia. Cualquier semejanza a sucesos, lugares y personas reales, vivas o fallecidas, es pura coincidencia". Véase también la "Nota del autor" Horacio Castellanos Moya (exiliado desde 1998) en la novela de dictador Tirana memoria: "Éste es un libro de ficción. Los caracteres principales son, pues, ficticios. No obstante, la escenografía histórica de la primera parte [...] así como muchas de las situaciones y personajes a los que se alude en ella, tienen su base en la historia de El Salvador en 1944. Debo aclarar que en este caso la historia ha sido puesta al servicio de la novela, es decir, la he distorsionado de acuerdo con los requerimientos de la ficción" (2008: 357). Lo cual viene a ilustrar el principio del double-decker y de la supeditación del marco de referencia externo al marco de referencia interno.

${ }^{13}$ La novela histórica propiamente dicha nace como especialización de la novela realista y, porque ambas se caracterizan por tematizar la realidad histórica extratextual, en ambos casos se puede hablar con propiedad de "mise en intrigue" (cf. Cohn 2001: 175).

${ }^{14}$ Cabe puntualizar que dicha intencionalidad extrarreferencial no excluye cierta voluntad de ejemplaridad: una reflexión de corte existencialista sobre las "situaciones" (en el sentido de Jean-Paul Sartre) y encrucijadas humanas, y sobre cómo personas que no tienen ninguna vocación heroica, sino mero sentido del deber, o de la decencia, llegan a actuar, en determinada situación, de manera heroica. 
histórica", ¿vamos a decir que se trata de una "novela de no-ficción”? Resultaría sin duda más adecuado, pero tampoco del todo satisfactorio.

En primer lugar, por lo inapropiado de la denominación "novela de no-ficción": aparte la dudosa expresión oximorónica (traducción de "non-fiction novel", que difundió T. Capote en el ámbito anglosajón), Noviembre no es novela (como acabamos de establecerlo) y, sí, incluye ficción (en el sentido de recursos novelescos -y algo más, como veremos).

En segundo lugar, porque Noviembre no se corresponde exactamente con lo que suele entenderse por "novela de no-ficción". En una de las mejores definiciones de este tipo de texto, F. Zipfel escribe:

Non-fiction novels are narratives depicting actual contemporary events and using the styles and techniques of fictional discourse. A story the author witnessed and / or investigated is presented in dialogues and dramatic scenes [...], from the point of view of the people involved [...], and it provides an immersive context in which the narration of actual events is as lively as the presentation of fictional worlds. (2005: 397)

A primera vista, semejante definición se aplica a Noviembre, pero Zipfel añade: "Unlike historical novels, non-fiction novels focus on contemporary themes and dispense with fictive story elements" (2005: 397). Estos dos últimos rasgos, que le sirven al crítico para diferenciar la no-ficción de la novela histórica (pero no me parecen criterios pertinentes para definir ésta) ${ }^{15}$, serían precisamente los dos discrepantes con respecto a Noviembre: la contemporaneidad de lo narrado y la ausencia de ficción (invención) en lo narrado.

En efecto, Noviembre evoca principalmente acontecimientos anteriores en veinticinco años a la escritura de la novela (y, de paso, otros anteriores, como los asesinatos de Óscar Romero y Rutilio Grande); es decir, habla de un Pasado que el autor, como el narrador-investigador, sólo ha conocido en parte, indirectamente, y que reconstruye a través de estudios y testimonios como podría hacerlo un historiador (o un novelista histórico).

Luego, con respecto a la ficción, hay que ponderar su peso exacto. Si bien Noviembre no debe considerarse como una ficción ni como una obra básicamente ficticia, resulta evidente que utiliza recursos propiamente novelescos tales como los que la (mal) llamada "non-fiction novel" ha tomado prestados de la novela; esto es: las escenas dramáticas, los diálogos imaginarios (pero con ambición de ser verídicos), la focalización interna ( perspectivas (composición caleidoscópica) ${ }^{16}$, el suspense y la sorpresa (por ejemplo, cuando un discurso se atribuye retrospectivamente a tal o cual personaje)... En algunas ocasiones, Noviembre va más allá; en especial cuando evoca, respectivamente en las partes segunda y cuarta, la infancia y los años de formación de "Miguel" y de "Juan", cuyas familias son representativas del pueblo llano y de su experiencia sufrida de la llamada Gran Historia. Ahí sí tenemos la impresión de que estamos leyendo una novela (histórica), incluso con un toque de realismo mágico: el narrador se complace en evocar ese mundo de la infancia que sueña con buques fantasmas $(57,66,86-88)$, duendes (93-95), gigantes (141). Si bien Miguel y Juan acabarán apareciendo como informantes del narrador, no cabe duda de que estos episodios incluyen "fictive story elements" (cf. Zipfel supra). Aparecen como discordantes, pero son funcionales: diría que vienen a desempeñar una función de contrapunto anímico, vital y esperanzador, en un relato fundamentalmente trágico; tal como lo hacen, por otra parte, a lo largo de la narración, las evocaciones sensibles y maravilladas de la Naturaleza (lo cual, por cierto, añade otra dimensión al título) ${ }^{17}$. Por otra parte, si bien todo invita a identificar al narrador-investigador con el autor (como hemos visto), en el texto de la novela hay un pequeño

\footnotetext{
${ }^{15}$ Para un ensayo de redefinición de la novela histórica, véase mi libro de 2013, en especial las pp. 28-55.

${ }^{16}$ Conviene precisar que la desmultiplicación de las perspectivas no permite, sin embargo, hablar de polifonía en el sentido propio (y ni siquiera de "imparcialidad" como hace el autor en varias presentaciones): el narrador no se limita a organizar las opiniones de los demás sino que opina él también, y se impone su perspectiva de denuncia (de hecho, las opiniones que nos hace escuchar convergen hacia una misma denuncia, desde luego muy comprensible).

${ }^{17}$ El título no remite sólo a los acontecimientos trágicos de noviembre de 1989, sino al mes de noviembre de cualquier año, que es y debe ser momento de rememoración y de conmemoración (deber de memoria), pero es también y ante todo una fase del ciclo de la Naturaleza, con las manifestaciones naturales propias del período. Encontramos semejante dinámica en el poema "Romero" (en El Círculo, pp. 18-19), que evoca el asesinato del "monseñor" arzobispo. El acontecimiento histórico, que "continúa temblando en el aire de marzo", es transfigurado por las numerosas y diversas referencias al mundo natural; en particular: una "bandada de cuervos" ha manchado la luz de "Su túnica blanca [que] es una playa de verano", pero "por algún lugar bajo el sol los ciervos se inclinan a beber".
} 
pasaje que apunta, indirectamente, a una diferencia: en función de la cronología de la p. 238, el narrador habría nacido hacia 1980, y no en 1973 (como J. Galán).

Así pues, Noviembre vendría a constituir un caso atípico de "non-fiction novel" (o, mejor, "narración parcialmente ficcional"): se centra en la evocación del pasado (median casi treinta años), e incluye una mayor dosis de ficcionalidad (sin que se pueda llegar a hablar de novela histórica, y menos aún de novela a secas).

Esto es: si bien la narración histórica parcialmente ficcional constituye de por sí un género híbrido formado por otros dos géneros intrínsecamente híbridos (la literature of fact o New Journalism y la novela histórica), la fórmula propuesta aquí lo es más aún, al acercarse en mayor medida a la novela histórica; además, participa de la literatura memorial y, en particular, testimonial, por los numerosos testimonios que integra el narrador, con distintos grados de transformación, dentro de su propio testimonio indirecto. ${ }^{18}$

Con respecto a esto último, no cabe duda de que el libro se inscribe dentro de una poderosa corriente centroamericana de literatura testimonial políticamente comprometida -desde los textos fundacionales de Miguel Barnet y Roque Daltón hasta la actualidad (cf. Werner Mackenbach 2015, con una copiosa bibliografía)-, pero hay que remontarse más allá, bajando hacia el sur del continente: el crítico no puede sino plantearse la cuestión del parentesco entre la presente evocación parcialmente ficcional de la masacre salvadoreña de 1989 y el famoso precedente argentino de Operación masacre (1957 en su edición original). Sabido es, en efecto, que con este libro tan valiente como novedoso (en su época), Rodolfo Walsh armó antes que Barnet y Dalton, y, por cierto, diez años antes que Truman Capote (In Cold Blood, 1966) y otros representantes del New Journalism (Norman Mailer, Tom Wolfe, etc.)- un ejemplo de narración parcialmente ficcional, y lo asentó con valor de paradigma en la literatura argentina y latinoamericana. En ambos casos, a raíz de un drama político-social (la masacre de un grupo de hombres que se manifestaron contra el poder establecido), el escritor emprende un libro de denuncia, en que se convierte en narrador y protagonista de una investigación que se apoya en los testimonios de quienes, directa o indirectamente, habían estado implicados en dicho drama, y son citados a comparecer. Hay diferencias, desde luego -en el caso de Operación masacre, los acontecimientos eran muy recientes (anteriores en apenas un año) y desconocidos del público, y por otra parte más limitado aún el componente ficcional-, pero éstas aparecen como marginales vistos la indudable semejanza y el parentesco objetivo (contemplara o no Jorge Galán el modelo del libro de Walsh).

Para concluir. El fenómeno de la hibridación poética no es nada nuevo, incluso constituye uno de los principios dinámicos de la historia literaria. En la tradición hispánica, se puede ver en Lope de Vega a uno de sus primeros teóricos (piénsese en El arte nuevo de hacer comedias en este tiempo, 1609). Es cierto, sin embargo, que los fenómenos de hibridación se han multiplicado a la par que se cuestionaban cada vez más los géneros tradicionales así como distinciones aparentemente tan fundamentales como poesía y prosa, o ficción y -para decirlo con G. Genette- dicción (diction) $)^{19}$. Además, la hibridación está de moda desde la supuesta postmodernidad (de la cual constituiría un rasgo definitorio), hasta el punto de representar una de las tendencias más significativas en lo que va del siglo $\mathrm{XXI}^{20}$. En España, quien más ha explorado sus posibilidades, y con más éxito, en el ámbito de la narrativa histórica (lato sensu), es probablemente Javier Cercas, desde Soldados de Salamina hasta El monarca de las sombras, pasando por Anatomía de un instante $^{21}$. Por lo tanto, frente a una fórmula híbrida más debemos preguntarnos cuál es su eficacia específica. En el caso de Noviembre, parece evidente: puesto que los objetivos declarados de Jorge Galán eran recordar (combinando denuncia y homenaje), conmover (inspirando una profunda simpatía, y el anhelo

${ }^{18}$ A la calificación de texto "híbrido" se podría preferir la de "mixto" (cf. A. Schmitt, "Le mythe de l'hybridité", 2010: 39-98, si bien a propósito de la autoficción), puesto que Noviembre se asienta fundamentalmente en una familia, la de los enunciados de realidad.

19 "Est littérature de fiction celle qui s'impose essentiellement par le caractère imaginaire de ses objets, littérature de diction celle qui s'impose essentiellement par ses caractéristiques formelles" (1991: 31): distinción de base que, desde el punto de vista terminológico, ofrece según Genette la doble satisfacción de la simetría y de la sustitución de non-fiction ("très gauche") por una palabra "commode et positive". Genette precisa que esta distinción teórica no excluye, en la práctica, diversas formas de hibridación (o de mezcla).

${ }^{20}$ R. Palumbo Mosca, que parte del "so-called 'return to reality' of Italian narrative starting from the 1990's", sugiere que "the flourishing [...] of narrations dealing with specific social issues by means of hybrid forms which consciously mix fiction and non-fiction should be read first of all as a reaction to the fictionalization of reality promoted by mass-media" (2013: 188-189) -lo cual invitaría a interpretar el fenómeno tanto como una manifestación de la postmodernidad, como una reacción a un aspecto de ésta: si los medios de comunicación convierten la realidad en espectáculo (el artefacto consumible y la neo-realidad de J. Baudrillard) y, en este sentido, en ficción, la literatura se hace cargo de dicha realidad, procurando rescatarla desde la misma ficción o con los medios de la ficción.

${ }^{21}$ No será una casualidad si la publicación española de Noviembre corre a cargo de la misma editorial y de la misma colección (Tusquets, “Andanzas”) que en 2001 acogieron Soldados de Salamina, por muy diferentes que sean textos, intenciones y contextos. Por cierto, ahí también se publicó en 2008 la novela histórica Tirana memoria, de Horacio Castellanos Moya, mencionada anteriormente (cf. nota 11). 
de justicia correspondiente) y comprometer (induciendo una respuesta social por parte de los lectores, los medios de comunicación e, in fine, idealmente, la Justicia salvadoreña), había que encontrar una fórmula que articulara, por una parte, todo el peso de lo real, incluso el de quien enuncia esta realidad (como en la literatura testimonial), y, por otra parte, toda la fuerza evocadora y persuasiva de la ficción (como en la "nonfiction novel" y en la "novela histórica"). De ahí esta fórmula ambigua, cuya virtud no es hermenéutica, sino performativa y pragmática. En particular, involucra al lector en una reflexión moral (sobre valores, comportamientos y responsabilidades), que conlleva, al menos potencialmente, consecuencias sociales ${ }^{22}$. El eco nacional e internacional del libro, y las mismas amenazas que llevaron al autor al exilio (como en los tiempos gloriosos de la littérature engagée), confirman el logro. Aunque el exilio sea sin duda vivido de manera muy dolorosa, se puede decir que, al optar por el exilio, el autor no sólo ha protegido su vida sino que ha podido reforzar el potencial pragmático del libro -lo cual no quiere decir, desde luego, que fuera cálculo suyo, pero sí mal cálculo de quienes lo amenazaron ${ }^{23}$.

\section{Referencias bibliográficas}

Bencastro, Mario (1997). Disparo en la cathedral. Houston: University of Houston.

Capote, Truman (1966). In Cold Blood. A True Account of a Multiple Murder and Its Consequences. Nueva York: Random House.

Castellanos Moya, Horacio (2008). Tirana memoria. Barcelona: Tusquets.

Cercas, Javier (2001). Soldados de Salamina. Barcelona: Tusquets.

Cohn, Dorrit (2001). Le propre de la fiction. Paris: Le Seuil, 2001 (The Distinction of Fiction, 1999).

Galán, Jorge (2014). El Círculo. Madrid: Visor.

Galán, Jorge (2016). Medianoche del mundo. Madrid: Visor.

Galán, Jorge (2016). Noviembre. Barcelona: Tusquets.

Genette, Gérard (1991). Fiction et diction. Paris: Le Seuil.

Hamburger, Käte (1957). Die Logik der Dichtung. Stuttgart: Ernst Klett Verlag.

Iribarren, Teresa (2016), "Mártires de la UCA. Novela enérgica y valiente sobre el pasado reciente de El Salvador", Catalunya Cristiana, 18 diciembre 2016, p. 12.

Lavocat, Françoise (2016). Fait et fiction. Pour une frontière. Paris: Le Seuil.

Liano, Dante (2017), "Jorge Galán: novela y memoria”, Centroamericana, vol. 27, nº 2, 2017, pp. 111-127.

Lefere, Robin (2013). La novela histórica: (re)definición, caracterización, tipología. Madrid: Visor.

Mackenbach, Werner (2015), "El testimonio centroamericano contemporáneo entre la epopeya y la parodia", Kamchatka. Revista de análisis cultural, 6 (“Avatares del testimonio en América Latina”), 2015, pp. 409-434.

Mackenbach, Werner, Rolando Sierra Fonseca y Magda Zaval (eds.) (2008). Historia y ficción en la novela centroamericana contemporánea. Honduras, C.A.: Ediciones Subirana.

Palumbo Mosca, Raffaello (2013), "Notes on Hybrid Novels and Ethical Discourse", Modern Language Notes, Volume $128, \mathrm{n}^{\circ} 1$, enero 2013 , pp. 185-205.

Pleitez Vela, TANIA (2015), “Tengo que volver a ser persona'. Conversación con Jorge Galán a propósito de su novela Noviembre", Istmo: Revista virtual de estudios literarios y culturales centroamericanos (sección "Foro debate"), $\mathrm{n}^{\circ} 31$ (julio-diciembre 2015).

Schmitt, Arnaud (2010). Je réel / Je fictif (Au-delà d'une confusión postmoderne). Toulouse: Presses universitaires du Mirail.

Walsh, Rodolfo (1957). Operación masacre. Buenos Aires: Sigla.

Zipfel, Frank (2005), "Non-Fiction Novel", en David Herman, Manfred Jahn \& Marie-Laure Ryan (eds.). The Routledge Encyclopedia of Narrative Theory. Londres \& Nueva York: Routledge.

\footnotetext{
${ }^{22} \mathrm{La}$ literatura no transforma el mundo pero sí -potencialmente, en la medida en que se comprometen en la lectura- a los lectores (afectiva e intelectualmente, en especial a través de una percepción y una conciencia del lenguaje agudizadas) y, a través de ellos -potencialmente, si el yo ciudadano no está escindido del yo lector (Sartre evocó el caso de esclavistas que habían llorado al leer La cabaña del tío Tom), y en la medida en que se compromete como ciudadano - transforma la sociedad.

${ }^{23}$ Si bien puede tratarse de una mera coincidencia, cabe señalar que el 13 de julio de 2016 la Corte Suprema de Justicia salvadoreña declaró inconstitucional la "Ley de Amnistía General para la Consolidación de la Paz" y reconoció la reviviscencia de la "Ley de Reconciliación Nacional". Por otra parte, el 16 de noviembre de 2017 el Tribunal Supremo de los USA ha dado luz verde a la extradición a España del ex coronel Inocente Orlando Montano, a todas luces implicado en el asesinato de los jesuitas españoles.
} 